\title{
As respostas do Porto de Itajaí à dinâmica da economia catarinense
}

Alcides Goularti Filho ${ }^{1}$

Resumo: O objetivo deste artigo é analisar como o Porto de Itajaí foi se ajustando à dinâmica da economia catarinense desde 1880 . O texto está dividido em sete tópicos, que mostram a evolução do Porto de Itajaí nos diversos momentos da economia catarinense. Grosso modo, podemos dividir o texto da seguinte forma: a) porto da colonização do Vale do Itajaí que atendia as demandas das colônias da região de Blumenau; b) porto madeireiro que se ajustou a uma das especializações regionais catarinenses; c) crise das atividades madeireiras e transição para uma economia diversificada; d) porto de carga geral, com destaque para cargas frigorificadas; e e) municipalização da gestão. A conclusão traz uma breve análise do impacto do porto na economia da cidade de Itajaí.

Palavras-chave: Porto de Itajaí; economia catarinense; projetos portuários; modernização portuária.

\section{The Itajaí Port and the evolution of Santa Catarina's economy}

\begin{abstract}
The objective of this article is to analyze the adaptations that the Port of Itajai went through in response to thee dynamics of the Catarinense economy since 1880 . The text is divided in eight topics that show the evolution of Port of Itajai at various moments of the Catarinense economy. Largely, the text can be divided as follows: a) the Port of the Itajaí Valley that attended to the demands from the territories in the Blumenau region; $b$ ) lumber port that adjusted to one of the regional specializations of Santa Catarina; c) the crisis in lumber activities and the transition to a diversified economy; d) general load port with focus on frozen
\end{abstract}

1 Doutor em Economia pela Unicamp. Professor da UNESC (Universidade do Extremo Sul Catarinense) junto ao Departamento de Economia. E-mail: alcides@unesc.net. Pesquisa financiada pelo CNPq e pela FAPESC. 
loads; and e) new local management. The conclusion summarizes the impact of the Port on the economy of Itajaí city.

Key words: Port of Itajaí; Catarinense economy; port projects; port modernization.

JEL: N760; N960

\section{Introdução}

O surgimento dos portos em Santa Catarina tem a ver com a demarcação, a ocupação e o povoamento do território catarinense. A instalação dos trapiches para ancorar as embarcações era condição necessária para a manutenção dos principais núcleos populacionais que foram surgindo ao longo do litoral de Santa Catarina. Durante todo o século XIX, os portos de Laguna, Desterro, Itajaí e São Francisco do Sul nunca tiveram expressão econômica nacional, sua importância era apenas local. Somente no final do século XIX é que os portos catarinenses passaram a ter mais destaque na economia brasileira. Durante a Primeira República, a divisão econômica dos portos catarinenses era a seguinte: Laguna e Imbituba exportavam carvão, Florianópolis exportava farinha, Itajaí exportava alimentos e madeira e São Francisco do Sul exportava erva-mate e madeira. Mesmo assim, esses produtos não eram expressivos no conjunto da pauta de exportação brasileira, em que se destacavam café, borracha, algodão, cacau e açúcar.

Nos anos de 1950 e 1960, o porto de Itajaí consagrou-se como o porto madeireiro; o de Imbituba, como carvoeiro; e os portos de Laguna, Florianópolis e de São Francisco do Sul passavam por momentos de crise sem uma especialização definida. Com o fortalecimento da grande indústria catarinense consolidando os setores eletro-metal-mecânico em Joinville e Jaraguá do Sul, têxtil-vestuário em Blumenau e Brusque, papel e celulose no Planalto, revestimentos cerâmicos em Criciúma e o complexo agroindustrial de carne no Oeste, os portos catarinenses ganharam um novo impulso.

Atualmente, Santa Catarina tem quatro portos com quatro sistemas administrativos diferentes: o Porto de São Francisco do Sul é administrado pelo governo estadual, o de Itajaí pela Prefeitura Municipal de Itajaí, o de Laguna pela Companhia Docas do Estado de São Paulo e o de Imbituba é um porto privado administrado pela Companhia Docas de Imbituba.

Dentro de uma perspectiva da longa duração e da dinâmica contraditória (Braudel 1998 \& Marx 1983), o objetivo deste texto é discutir como o Porto de Itajaí foi respondendo às dinâmicas engendradas na economia catarinense, que inicialmente apresentava uma forte especialização regional e que em seguida desdobrou-se numa diversificação produtiva, integrando-se no mercado interno e externo. Em cada um desses momentos (especialização, diversificação e integração), predominou um padrão de crescimento na economia catarinense. O primeiro período, de 1880 a 1945, caracterizou-se pela origem e crescimento do capital industrial. O segundo, de 1945 a 1962, foi marcado pela diversificação e ampliação da base produtiva. O terceiro período começa 
depois de 1962 e segue até 1990, quando ocorreu a integração e a consolidação da indústria catarinense. O último período iniciou em 1990 com a abertura comercial e financeira e a desregulamentação da economia.

Num movimento lento de transformações estruturais (Braudel 1998), em dois séculos, o Porto de Itajaí passou por profundas alterações. No século XIX, o rio da colonização do Vale do Itajaí abrigava na sua foz um pequeno porto que servia de elo entre as colônias e o resto do país. Esse porto cresceu junto com a cidade e em meados do século XX transformou-se num grande porto madeireiro. Após passar por crises e desastres, hoje o Porto de Itajaí ainda resiste e é o maior do estado.

\section{O porto da colonização do Vale do Itajaí}

Itajaí foi fundada no início dos anos 1820, na foz do Rio Itajaí-Açu, por açorianos pescadores. O Rio Itajaí-Açu tem vários afluentes e apresenta condições de navegabilidade em alguns trechos, e durante muito tempo serviu de caminho natural para ligar Itajaí a Blumenau. Na foz do rio, o porto e a vila foram se constituindo juntos, e a expansão da segunda estava relacionada com o crescimento do primeiro. A bacia hidrográfica do Rio Itajaí-Açu é a maior de Santa Catarina, com uma extensão de $15.500 \mathrm{~km}^{2}$, destacando-se os afluentes Itajaí-Oeste, Itajaí-Sul, Itajaí-Norte (ou Hercílio) e Itajaí-Mirim.

Na época da grande imigração, no último quartel do século XIX, parte do contingente de imigrantes que chegou ao Brasil destinou-se para o complexo cafeeiro paulista, que estava em franca expansão. O amplo sistema ferroviário paulista e o Porto de Santos criaram condições concretas para a expansão da cafeicultura, que por sua vez permitia a fixação dos imigrantes nas fazendas e nas cidades (Cano 1990). Para o Brasil meridional, também foi destinado um razoável contingente de imigrantes para colonizar o Rio Grande do Sul - serra gaúcha e Vale do Rio dos Sinos -, Santa Catarina - litoral e planalto norte, Vale do Itajaí e sul - e o Paraná - região de Curitiba. Nos três estados, os novos imigrantes fundaram vilas e desenvolveram pequenas atividades mercantis. Com a ampliação dessas atividades mercantis, rapidamente as colônias se integraram comercialmente com outros centros urbanos maiores (Castro 1980). Estradas, rios e ferrovias foram as vias de comunicação utilizadas pelos imigrantes para escoarem a produção das colônias.

Em Santa Catarina, o Vale do Itajaí foi mais ocupado, sobretudo com a chegada da segunda grande leva de imigrantes pós-1880, apesar de Blumenau e Brusque terem sido fundadas em 1850 e 1860, respectivamente. A chegada de mais imigrantes contribuiu para diversificar a economia na província, com o surgimento de novas atividades comerciais e artesanais (pequena produção). A presença de várias pequenas atividades mercantis e manufatureiras (artesanato, pequena indústria) formava um sistema colônia-venda que contribuiu para gerar nas colônias uma acumulação pulverizada e lenta. Na pequena propriedade, os imigrantes produziam a subsistência para suas famílias e mer- 
cantilizavam o excedente com o intuito de acumular. O mercado consumidor para esse excedente era a sua hinterland. Com a ampliação do sistema colôniavenda, começaram a surgir as primeiras casas comerciais e as pequenas oficinas de abrangência regional. No começo do século XX, o excedente passou a ser exportado para centros comerciais maiores, como Florianópolis, São Paulo e Rio de Janeiro. As exportações concentravam-se na banha, nos derivados de suínos, na manteiga, na madeira e nos têxteis (Mamigonian 1965).

Nessa época, grande parte da produção das colônias do Vale do Itajaí era escoada pelo Porto de Itajaí. O contato de Blumenau com o porto era feito pelo Rio Itajaí-Açu. O rio, o porto e a Vila de Itajaí serviam de via de comunicação e base de transporte para as colônias do Vale. Além de base de exportação, pelo porto também chegavam os imigrantes e as mercadorias e ferramentas necessárias para a colonização.

É bom lembrar que no início do século XIX o litoral catarinense estava mais densamente ocupado em apenas três pontos dispersos: no sul, em Laguna; no centro, em Desterro; e no norte, em São Francisco do Sul. Além desses três municípios, também havia vários pequenos núcleos populacionais que se formaram em função da pesca da baleia (CEAG/SC 1980). Portanto, além de dar suporte para a colonização do interior, a consolidação da vila e do Porto de Itajaí também interessava ao governo da província de Santa Catarina, que almejava ocupar mais densamente o litoral. A relação que Joinville e as colônias do planalto norte tinham com o Porto de São Francisco do Sul, dentro do complexo ervateiro, era quase a mesma que Blumenau tinha com o Porto de Itajaí.

\section{Construção e melhoramentos do porto madeireiro}

Podemos pensar a economia catarinense entre 1880 e 1945 como a fase de origem e crescimento do capital industrial. Nesse período predominava a pequena produção mercantil e a extração da erva-mate, da madeira e do carvão, além da indústria têxtil e da alimentar. A erva-mate extraída, transportada e beneficiada em Santa Catarina fazia parte do grande complexo ervateiro do Paraná. Parte da produção da erva era escoada via fluvial pelo Rio Iguaçu e pelo Rio Negro, que seguia pela Estrada Dona Francisca e pelo ramal ferroviário da Estrada de Ferro São Paulo-Rio Grande até a cidade de Joinville, onde era beneficiada para depois ser despachada pelo Porto de São Francisco. Esse complexo começou a ser desmontado após 1930, com a queda nas exportações da erva-mate. A madeira, basicamente a araucária, era extraída no oeste catarinense e escoada pelo Rio Uruguai, para a Argentina, e pela Estrada de Ferro São Paulo-Rio Grande. Quando esgotaram as reversas florestais da região, a partir dos anos de 1940, as atividades madeireiras deslocaram-se para o planalto serrano. O carvão mineral era extraído das minas no sul catarinense e transportado pela Estrada de Ferro Dona Tereza Cristina até os portos de Laguna e Imbituba. Os alimentos e os têxteis concentravam-se nas cidades de Blumenau e Brusque, que comercializavam com várias cidades catarinenses e de outros estados (Goularti Filho 2002). 
Como conclusão desse movimento, podemos olhar para Santa Catarina nesse período como uma economia especializada em que cada porto atendia sua hinterland reforçando a especialização. A partir da segunda metade dos anos de 1910 até o final dos anos de 1920, no geral, o valor das exportações catarinenses aumentou em seis vezes, ritmo que se manteve na década de 1930. Das mercadorias transportadas pelo Porto de Itajaí, tivemos o seguinte desempenho: a) a madeira aumentou em mais de 22 vezes; b) os têxteis (camisas de algodão, fio de algodão, meias de algodão e de seda) aumentaram oito vezes; e c) os alimentos em geral aumentaram como um todo: o feijão oito vezes, a banha cinco vezes, a manteiga quatro vezes e meia, o arroz duas vezes e meia e o queijo nos anos 20 aumentou três vezes e meia. No geral, o aumento das exportações catarinenses do Vale do Itajaí para o mercado interno até os anos de 1930 deve ser entendido a partir das seguintes mudanças: a) a expansão do complexo cafeeiro e seus desdobramentos na expansão urbana em São Paulo; e b) o forte processo de diversificação econômica ocorrida nos anos de 1920 em São Paulo e no Rio de Janeiro com o surgimento de novas indústrias. Ou seja, Santa Catarina respondia positivamente ao aumento da demanda nacional (Goularti Filho 2002). Na tabela abaixo, podemos acompanhar a participação das principais mercadorias exportadas por Santa Catarina no período de 1895 a 1940.

TABELA 1 -PARTICIPAÇÃODASPRINCIPAISMERCADORIASEXPORTADAS POR SANTA CATARINA - 1895-1940 (EM \%)

\begin{tabular}{ccccccccc}
\hline ANO & ERVA MATE & MADEIRA & ALIMENTOS & CEREAIS & TECIDO & SOMA & OUTROS & TOTAL \\
\hline 1895 & 28,2 & 8,2 & 15,1 & 27,2 & & 78,7 & 21,3 & 100,0 \\
1900 & 31,8 & 4,2 & 21,9 & 25,5 & 0,1 & 83,5 & 16,5 & 100,0 \\
1905 & 24,6 & 9,2 & 21,4 & 19,0 & 2,3 & 76,5 & 23,5 & 100,0 \\
1910 & 18,7 & 9,1 & 41,5 & 14,2 & & 83,5 & 16,5 & 100,0 \\
1915 & 6,9 & 2,3 & 19,5 & 32,1 & 6,2 & 67,1 & 32,9 & 100,0 \\
1920 & 13,2 & 10,0 & 14,4 & 13,8 & 5,7 & 57,0 & 43,0 & 100,0 \\
1925 & 8,3 & 13,6 & 18,8 & 22,3 & 9,5 & 72,4 & 27,6 & 100,0 \\
1929 & 16,2 & 15,1 & 20,2 & 13,8 & 8,5 & 73,8 & 26,2 & 100,0 \\
1935 & 4,2 & 16,0 & 22,9 & 15,5 & 11,3 & 69,9 & 30,1 & 100,0 \\
1940 & 3,3 & 24,8 & 10,4 & 10,8 & 17,4 & 66,6 & 33,4 & 100,0 \\
\hline
\end{tabular}

FONTE: Goularti Filho (2002:435)

\subsection{Como o Porto de Itajaí respondeu a essa dinâmica imposta pela especialização regional catarinense?}

A primeira ligação entre o Vale de Itajaí e o porto foi o próprio Rio ItajaíAçu. A navegação de pequenas embarcações era o transporte mais utilizado na comunicação entre Blumenau com Itajaí, único trecho navegável do rio. Como o porto era o portal de entrada para as colônias, manter uma estreita relação com ele era condição necessária para a manutenção da própria colônia. Para agilizar a comunicação e aproximar Itajaí e Blumenau, em 1878 foi constituída a Companhia de Navegação Fluvial a Vapor Itajaí-Blumenau, que 
regularmente saía de Blumenau, passava por Gaspar até chegar à cidade de Itajaí, num percurso de 72,3 quilômetros. Pelos paquetes (pequenos barcos a vapor) "Progresso" e "Blumenau" e nas barcas anexadas, eram transportadas mercadorias.

Em janeiro de 1903, a Comissão de Melhoramentos do Porto de Santa Catarina baixou uma instrução para que fossem feitos melhoramentos no porto da capital e nas barras de Laguna, Palhoça e Itajaí. No Rio Itajaí-Açu, foram feitos levantamentos desde a foz até cinco quilômetros rio acima para observar as modificações ocorridas desde 1896, data do último levantamento (Brasil 1904).

As condições da barra do rio estavam cada vez mais precárias, em função do crescimento do pontal. Na comparação com o levantamento feito em 1896, havia um avanço na extremidade do pontal e corrosão da margem fronteiriça da cidade, por isto seria necessário forçar a curvatura da linha de navegação ao transpor a extremidade. Porém, isso impediria a entrada de navios grandes e a travessia de navios pequenos quando a correnteza do rio fosse grande (Brasil 1906). Finalmente, em 1905, foi elaborado o primeiro projeto para "restabelecer o franco acesso ao Porto de Itajaí, para vapores de grande comprimento" (Brasil 1907:771). As obras previstas seriam a construção de três molhes (quebra-mar) para impedir a corrosão feita pelo rio na margem fronteiriça à cidade e outro molhe na margem oposta à extremidade do pontal de areia (Brasil 1907).

As obras do Porto de Itajaí foram respaldadas pelo regime jurídico portuário de 1903, em que o governo ficava responsável pela obras dos portos e em seguida poderia conceder à iniciativa privada por 10 anos (Brasil 1903). Entre 1907 e 1916, as obras na barra e no porto foram executadas pela Comissão de Estudos e Obras do Porto de Santa Catarina, principalmente o molhe, o cais e a dragagem, e seguiram um ritmo constante, ora mais acelerado, ora mais lento. Para o governo federal, as obras seguiam o ritmo desejado, mas para o governo estadual os recursos disponíveis estavam muito aquém do necessário (Santa Catarina 1913). Em 1917, novamente, como em todo o país, as obras pararam por falta de recursos devido à Primeira Guerra Mundial. As obras ficaram paralisadas durante os quatro anos da guerra, o que resultou num prejuízo de equipamentos danificados, como guindastes, locomotivas e embarcações (Brasil 1918). Durante o ano de 1920, quando as obras foram retomadas, foram construídos 236 metros de molhe, sendo 174 na margem direita (Brasil 1922:326). As obras continuaram até 1925, quando novamente foram paralisadas por falta de verba. Nesse ínterim, a Comissão do Porto de Itajaí, que tinha sede em Florianópolis, foi anexada pela Fiscalização do Porto de São Francisco.

Em 1920, o engenheiro Edgard Gordilho elaborou uma inspeção nos portos do sul do país. Gordilho argumenta que, entre os portos de Santa Catarina, o de Itajaí era o único que tinha condições naturais de se "transformar num 
excelente porto". O problema era a entrada da barra, já que o rio oferecia "magnífico ancoradouro". As duas questões principais a resolver na barra eram:

1. Resolver o problema de sua entrada ou canal da barra, de modo que os navios possam transpô-lo sem dificuldades que apresentam a manobra, em virtude do cotovelo fortíssimo a que o pontal de areia da margem esquerda dá lugar.

2. Evitar o solapamento contínuo das margens do rio a montante da cidade, que pode, de um momento para outro, atingir a própria cidade. (Gordilho apud Ministério da Viação e Obras Públicas 1922:239)

Ojogo da força do rio e do mar que operavam sobre o canal mantinha uma "situação de equilíbrio". Uma era a contínua massa de areia que obstruía a entrada do canal e a outra era a correnteza do rio que destruía a massa de areia. Gordilho discordava do projeto elaborado pela Comissão de Estudos e Obras dos Portos de Santa Catarina e defendia que fosse prevista a construção de guias-correntes na margem direita do Rio Itajaí-Açu, prolongando em curva até encontrar o pontal arenoso na margem esquerda, de maneira a limitar a foz do rio e reduzir a curvatura.

Com base nos estudos de Manuel da Silva Couto e Lothário Hehl, a IFPRC (Inspetoria Federal de Portos, Rios e Canais 1935) elaborou um novo projeto para o Porto de Itajaí, que foi aprovado pelo Decreto 17.344 de 9 de junho de 1926, cujo orçamento previsto era de 3.307.465.500. No ano seguinte, o Ministério da Viação e Obras celebrou o contrato com a Companhia de Mineração e Metalurgia do Brasil (Cobrasil) para executar as obras do Porto de Itajaí.

As obras iniciaram no dia 8 de agosto de 1927 com a retirada de rocha da pedreira Queimada e a alteração do guia-corrente. As expectativas eram que, solucionados os problemas do acesso ao porto e executadas as obras previstas, o movimento comercial do porto poderia ser atendido pelos "trapiches existentes" e por outros que poderiam vir a ser construídos (Ministério da Viação e Obras Públicas 1928: 102). Porém, no ano seguinte, a obra seguiu num ritmo muito lento pela falta de equipamentos adequados da Cobrasil. Em seguida, houve uma revisão do contrato, e foram impostas ao contratante "obrigações estritas para se aparelhar em curto prazo e atacar com intensidade as obras" (Ministério da Viação e Obras Públicas 1932:96).

A execução dos melhoramentos previstos teve um andamento satisfatório até outubro de 1930, quando as obras dos portos de Itajaí, Laguna e São Francisco do Sul foram paralisadas por motivos de irregularidades (Inspetoria Federal de Portos, Rios e Canais 1932). Porém, a Cobrasil respondeu às acusações contra-argumentando problemas nas condições físicas da obra, distorção de preços e modificações no contrato (Cobrasil 1931).

Se pensarmos o sistema portuário nacional nesse período, a Primeira República herdou um sistema portuário fragmentado e em precárias condições, com portos e trapiches espalhados ao longo da costa sem condições, de suportar o aumento do fluxo de carga. Desde o Porto de Manaus, passando por Recife, Salvador, Rio de Janeiro, Santos e chegando até os pequenos trapiches no 
sul do Império, todos necessitavam de melhoramentos, segurança e recursos humanos. Durante o período de 1910 a 1934, que foi caracterizado pelo início da nacionalização dos problemas portuários com a centralização das tomadas de decisões, podemos destacar dois avanços para os portos: a criação da IFPRC (Inspetoria Federal dos Portos, Rios e Canais) em 1910 e a aprovação do Regulamento dos Portos Organizados em 1922. Quando da aprovação do Regulamento, mesmo tendo como móvel da acumulação o capital mercantil agrário e exportador, a economia brasileira passava por um processo de diversificação econômica, sem que esta fosse acompanhada das devidas melhorias nos portos. (Goularti Filho 2006).

Em 1930, o inspetor Hidelbrando de Araújo Góes publicou um livro/relatório no qual expressou bem o espírito de mudança da época, pautado numa maior atuação do Estado na economia e na centralização das tomadas de decisões. Segundo Góes, o governo federal deveria abandonar a velha política de pensar o melhoramento dos portos, que era fragmentada e desarticulada, para pensar uma nova política centralizada e hierarquizada. A falta de "planejamento" de uma política portuária nacional levou à superabundância de diversos portos na costa brasileira, construídos de forma aleatória e sem relação econômica com a sua hinterland. Cada estado, além de pleitear o melhoramento de seu porto principal, para atender a interesses locais, defendia a construção de novos portos para atender a demandas específicas. Muitas vezes, era ignorada a presença de um porto no estado vizinho, que facilmente poderia atender às demandas específicas para contemporizar os compromissos políticos. Góes defendia que os portos deveriam ser classificados numa hierarquia, destacando os principais portos organizados e sua grande área de abrangência. Os pequenos portos tributários deveriam ter um caráter "nitidamente temporário", e seu funcionamento dependeria da "marcha evolutiva das necessidades de cada um deles" (Góes 1930:7). Essa foi a visão que norteou a política portuária brasileira nas décadas seguintes.

O Estado que surgiu após a Revolução de 1930, além de ampliar a sua base de atuação, passou a centralizar, burocratizar e racionalizar ainda mais as suas funções. Do ponto de vista econômico, os anos de 1930 inauguram também um novo padrão de acumulação, o da industrialização restringida. Já podemos falar em industrialização, porém ela é limitada pela baixa capacidade de importar e pelas débeis bases técnicas e financeiras, cuja acumulação era horizontal, e, portanto, incapazes de comandarem e financiarem os investimentos necessários para o país constituir "forças especificamente capitalistas de produção” (Cardoso de Mello 1988).

Apesar de Santa Catarina exportar madeira desde o século XIX, podemos afirmar que até 1930 o Rio Itajaí-Açu e o Porto de Itajaí eram o escoadouro natural da produção agrícola e manufatureira do Vale do Itajaí e, em menor escala, da madeira que descia pelo Rio Itajaí-Açu. Nos anos 1940, 1950 e 1960, Itajaí se consagrou como o maior porto madeireiro do país. Com a exploração acelerada da araucária 
no planalto serrano, ampliaram as exportações de madeira no estado. Em boa medida, a madeira era escoada para o Centro-Oeste (construção de Brasília) e Sudeste do país pela BR-116, para o Porto de São Francisco do Sul, via ferroviária partindo de Mafra, ou para o Porto de Itajaí, descendo de caminhão pela BR-470 até Itajaí ou até Blumenau, de onde seguia pela via fluvial. A tabela abaixo traz a participação da madeira na pauta de exportações catarinenses.

\begin{tabular}{|c|c|}
\hline ANO & PARTICIPAÇÃO \\
\hline 1945 & 67,5 \\
\hline 1950 & 60,0 \\
\hline 1955 & 64,0 \\
\hline 1960 & 68,4 \\
\hline 1965 & 79,0 \\
\hline 1970 & 61,6 \\
\hline
\end{tabular}

FONTE: Goularti Filho (2002:146)

A resposta de Porto de Itajaí à economia catarinense foi acelerar as obras para atender às demandas da economia madeireira. Conforme os relatórios do DNPRC (Departamento Nacional de Portos, Rios e Canais), durante os anos 1940 as obras seguiram um ritmo constante para se adaptar ao aumento das exportações de madeira. No período de 1941 a 1950, foram promulgados sete decretos aprovando novos orçamentos e obras complementares. A Cobrasil entregou para o DNPRC as obras em 1949, quando já estavam concluídos 233,6 metros lineares de cais acos-

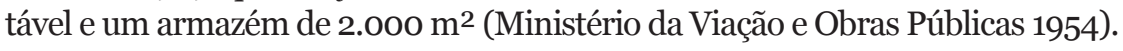

Em 1950, pelo Decreto 28.468, foi aprovado mais um orçamento para o prolongamento de 270 metros de cais acostável e obras complementares no Porto de Itajaí na ordem de 45 milhões de cruzeiros. Essa obra foi concluída no mesmo ano. Finalmente, em 1956 foram concluídos mais 200 metros de cais acostáveis e o frigorífico destinado aos pescados.

\section{Porto organizado e crise da madeira}

A partir de 1934, temos que pensar a evolução dos portos dentro do "projeto nacional de industrialização" comandada pelo Estado brasileiro. Do ponto de vista institucional, ocorreram quatro mudanças: a criação do DNPN (Departamento Nacional de Portos e Navegação) em 1934, alterado em 1943 para DNPRC (Departamento Nacional de Portos, Rios e Canais), transformado em autarquia em 1963 como DNPVN (Departamento Nacional de Portos e Vias Navegáveis) e em Portobras (Empresa de Portos do Brasil S.A.) em 1975, uma empresa holding. Do ponto de vista jurídico, foram instituídos dois regimes portuários. O primeiro foi com o Decreto $24.599 \mathrm{em} 1934$, em que o governo ficava autorizado a contratar para o melhoramento e exploração dos portos, 
por meio da concessão, os estados ou empresas privadas num prazo nunca superior a 70 anos; e o segundo, com o Decreto-Lei 749 em 1969 que autorizava a União a formar sociedade de economia mista ou empresa pública destinada a explorar os portos, terminais e vias navegáveis.

Durante os anos 1950 a 1980, passamos por vários regimes políticos, mas, até 1980, seguiu ininterruptamente um longo período de industrialização, e o período restante, 1980-1990, foi de manutenção do parque industrial instalado. Nesse longo período de industrialização, o Estado brasileiro assumiu formas superiores de organização capitalista, orientando o processo de acumulação por meio do planejamento e do financiamento, além de políticas cambiais (orçamento cambial) e monetárias mais flexíveis voltadas para o crescimento. O Plano de Metas (1956-1961) e o II PND (1975-1978) são dois exemplos que cristalizaram os objetivos do Estado para a formação, segundo List (1986), de um sistema nacional de economia.

Dentro desse movimento em torno do planejamento e com a criação do DNPVN, finalmente o Porto de Itajaí foi declarado porto organizado pelo Decreto 58.780 de 28 de junho de 1966. O mesmo decreto criou a Junta Administrativa do Porto de Itajaí (JAPI), que seria responsável pela gestão e operação das atividades portuárias. A justificativa de organizar o porto era sua importância comercial e industrial do Vale do Itajaí e a necessidade de integrá-lo no sistema portuário nacional (Decreto 58.780/1966).

Além de a JAPI ter a função de executar os serviços de exploração comercial do porto, também deveria realizar obras de melhoramentos ou ampliação das instalações portuárias. No momento em que foi declarado porto organizado, o porto de Itajaí tinha 700 metros de cais acostável e se preparara para enfrentar a sua maior crise: a queda nas exportações da madeira.

Se até 1945 poderíamos olhar para Santa Catarina com uma economia especializada, nos anos seguintes essa realidade começou a alterar substancialmente. No período 1945-1962, assiste-se, na economia catarinense, a uma verdadeira diversificação e ampliação da base produtiva. Há uma diversificação porque surgem novos setores como os de papel, papelão, pasta mecânica, cerâmico, metal-mecânico, materiais elétricos e indústrias ligadas ao setor de transporte. Há uma ampliação porque: a) os setores como os de papel, papelão, pasta mecânica, móveis e metal-mecânico, que nasceram antes ou nos anos de 1930, aumentaram a sua produção, e também surgiram novas indústrias; b) os setores carbonífero e têxtil ampliaram a capacidade produtiva; e c) a agricultura começou a se industrializar, transitando do complexo agrocomercial para o complexo agroindustrial. Os setores com potencialidades mais dinâmicas, o metal-mecânico, o cerâmico e a produção de papel e pasta mecânica, nascem da pequena produção e volta-se para o mercado nacional, expandindo-se rapidamente, num momento em que a industrialização pesada estava num processo acelerado de expansão e consolidação. Porém, a pauta de exportação catarinense era composta em torno de 70,0\% de madeira. As 
novas mercadorias produzidas em Santa Catarina (azulejos, papel, peças e equipamentos) eram destinadas basicamente para o mercado interno (Goularti Filho 2002).

No final dos anos 1960, o ritmo da extração de madeira começou a apresentar uma queda, revertendo a longa tendência de crescimento desde o início do século. Em 1970, a madeira representou 61,6\% das exportações catarinenses; em 1972, caiu para 45,8\%; em 1974, para 26,5\%; e em 1976, para 4,5\%. Ou seja, em apenas seis anos, as exportações de madeira caíram 92,7\%. No entanto, ao mesmo tempo em que caíam as exportações de madeira, Santa Catarina começava a exportar motores elétricos e alimentos congelados. No final dos anos 1970, o Porto de Itajaí já estava adaptado às novas demandas: azulejos, motores e alimentos congelados (Goularti Filho 2002).

\begin{tabular}{cccc} 
TABELA $3-$ PARTICIPAÇÃODASPRINCIPAISMERCADORIASEXPORTADAS \\
POR SANTA CATARINA $-1970-1980$ (EM \%) \\
\hline MERCADORIAS & 1970 & 1975 & 1980 \\
\hline Açúcar refinado & - & 15,5 & 18,4 \\
Farelo de soja & 2,1 & 4,3 & 16,6 \\
Têxtil e vestuário & 1,5 & 16,5 & 13,8 \\
Carnes e miudezas & - & 1,3 & 11,6 \\
Fumo em folha & 8,9 & 16,1 & 9,2 \\
Óleo de soja & - & 3,4 & 6,0 \\
Madeira pinho serrada & 57,5 & 14,6 & 5,0 \\
Camarão fresco & 2,7 & - & 1,0 \\
Obras de carpintaria & 4,1 & 3,6 & - \\
Outros & 23,2 & 24,7 & 18,4 \\
Total & 100,0 & 100,0 & 100,0 \\
\hline
\end{tabular}

FONTE: Goularti Filho (2002:483)

A queda exponencial das exportações de madeira, que gerou uma alta capacidade ociosa no Porto de Itajaí, coincidiu com a criação de vários incentivos e subsídios para a pesca gerenciados pela Sudepe (Superintendência para o Desenvolvimento da Pesca). A pesca artesanal em Itajaí passou por uma rápida transformação com a expansão da indústria pesqueira e o aumento de barcos mais equipados. O pequeno terminal pesqueiro foi ampliado, e, na época, como saída para a crise da madeira, pensava-se em transformar o Porto de Itajaí num porto pesqueiro. Mas a ampliação das exportações catarinenses trouxe um novo fôlego para o porto e a cidade de Itajaí. Na Tabela 3 podemos observar a queda substancial nas exportações de madeira e a ampliação de carnes e miudezas, derivada do complexo agroindustrial do oeste catarinense. 
Se até os anos de 1960 o Porto de Itajaí atendia à especialização regional catarinense baseada na madeira, como o porto respondeu ao rápido processo de diversificação da estrutura produtiva catarinense?

\section{Planejamento e diversificação produtiva}

O padrão de crescimento da economia catarinense alterou a partir de 1962, com a criação de um novo sistema de crédito estadual, com os investimentos em energia e transporte comandados pelo Estado e com a consolidação do setor eletro-metalmecânico, liderado pelas médias e grandes indústrias. Mesmo nos setores tradicionais, várias firmas se consolidaram, incorporaram outras marcas, tornando-se líderes nacionais. Internamente, o movimento geral da indústria catarinense passa a ser conduzido por grandes e médias empresas nos setores de alimentos (Sadia, Perdigão, Chapecó, Coopercentral, Seara e Duas Rodas), eletro-metal-mecânico (Tupy, Consul, Embraco, WEG, Kohlbach, Busscar e Duque), cerâmico (Eliane, Cecrisa, Icisa, Portobello e Cesaca), têxtil-vestuário (Hering, Artex, Karsten, Teka, Sulfabril, Malwee, Renaux, Buettner, Cremer, Marisol, Malwee e Döhler), papel e celulose (Klabin, Igaras, Irani, Trombini e Rigesa), madeireiro (Sincol, Adami, Battistella e Fuck), carbonífero (CBCA, CCU, Metropolitana, Criciúma, Catarinense e Próspera), moveleiro (Cimo, Artefama, Rudnick e Leopoldo), plástico (Hansen - Tigre e Cipla -, Canguru e Akros) e porcelanas e cristais (Oxford, Schmitz, Ceramarte, Blumenau e Hering). A mudança do padrão de crescimento em Santa Catarina só pode ser entendida, em primeira instância, pela mudança do padrão de acumulação em nível nacional, que tinha como tripé básico o capital estatal, o externo e o nacional. Em 1962, começa um novo período em Santa Catarina, quando o capital industrial passa a ser o móvel da acumulação capitalista. A modernização da agricultura, com a mutação do complexo agrocomercial para o complexo agroindustrial de carne, reforça e consolida o novo padrão de crescimento em Santa Catarina, comandado pelo Estado e pelas grandes e médias indústrias e agroindústrias (Goularti Filho 2002).

Após queda brutal nas exportações na madeira, o Porto de Itajaí teve que se adaptar a esse novo padrão de crescimento da economia catarinense. No início dos anos de 1970, a grande indústria catarinense estava se preparando para conquistar e ampliar a sua participação no mercado externo. Em âmbito nacional, o país estava engrenado num rápido crescimento econômico coordenado e orientado pelo Estado por meio do planejamento.

Paralelos aos planos nacionais de desenvolvimento elaborados e executados nos anos de 1950 a 1980, foram realizados diversos estudos sobre o sistema portuário nacional que resultaram na produção de diversos planos portuários comandados a partir dos interesses nacionais. Os planos portuários respeitavam a hierarquia portuária deixando de lado muitos portos regionais, como, por exemplo, o Porto de Itajaí não foi incluído nos três primeiros planos. Com o término da construção e após ter declarado porto organizado, finalmente, o Porto de Itajaí passou a fazer parte dos planos portuários. No Plano Portuário 
Nacional 1963-1966 Itajaí foi incluído no item "Expansão e Melhoramento". Itajaí também foi incluído no Plano Diretor Portuário do Brasil de 1974 e no Plano de Desenvolvimento Portuário de 1986. Dentro do Plano Diretor Portuário do Brasil e do Programa Decenal de Reaparelhamento e Expansão dos Portos para o período de 1975 a 1984, para o Porto de Itajaí estava previsto um orçamento de 9 milhões de cruzeiros para serem aplicados em "obras gerais de recuperação incluindo novo armazém para carga geral e aquisição de equipamentos" (Ministério dos Transportes 1974:133). Essas obras eram para atender às novas demandas, e em 1977 foi entregue o armazém três e recuperado/reformado o frigorífico (Ministério dos Transportes 1986).

Quando o DNPVN foi extinto, em 1975, a Portobras passou a administrar diretamente o Porto de Itajaí, criando a Administração do Porto de Itajaí (API), que assumiu todas as funções da JAPI.

No Plano Diretor reelaborado em 1979, a partir do Plano de 1974, as conclusões não foram muito animadoras para Itajaí. O Plano recomendava que não deveria ser feita nenhuma expansão física sem antes esgotar todo o potencial do porto e concluía que esse potencial era extremamente limitado, e predominaria a movimentação de carga geral.

Dadas as limitações de calado, a ausência de acesso ferroviário e a grande proximidade do porto de São Francisco do Sul, o porto de Itajaí deverá manter ao longo do tempo uma composição de tipos de carga semelhante àquela verificada até o presente, com a predominância da movimentação de carga geral. (Ministério dos Transportes 1979:52-3) Se houvesse a intenção de continuar se especializando em carga geral, a recomendação do Plano era que fosse recuperada a estrutura do cais, que estava em estado muito precário, e também deveria ser aprofundado o acesso para embarcações de maior calado. Com relação à movimentação de contêineres, que estava apenas começando, a previsão era que no futuro o porto de Itajaí poderia tornar-se um porto alimentador-receptor de Santos. As recomendações também não foram animadoras e colocavam Itajaí numa posição inferior a São Francisco do Sul, e sua hinterland limitada apenas ao Vale do Itajaí. (Ministério dos Transportes 1979:79).

O Plano de Desenvolvimento Portuário de 1986 reforçou a posição de Itajaí como apenas um porto regional que participava do "esforço de exportação da região, embarcando mercadorias para o exterior do país e por outro lado introduz na região produtos nacionais" destinados às indústrias locais (Ministério dos Transportes 1986).

Os fatores limitantes do nível de serviços eram basicamente operacionais, destacando a dragagem junto ao cais e a bacia de evolução. Outras deficiências eram:

A falta de equipamentos especializados e pátios específicos para a movimentação e estocagem de containeres, a ocorrência de espera, dificultando a atracação imediata, decorrente da falta de cais acostável, o sistema elétrico não adequado às operações do porto e a falta de guindastes com a capacidade para 1ot a serem utilizados na descarga de granéis. (Ministério dos Transportes 1986:18)

A previsão mais otimista, talvez, fosse o aumento acentuado de navios full-conteiner a partir de 1984 . 
Cumprindo as recomendações do Plano Diretor de 1979, em 1981, se iniciaram as obras de "recomposição de peças e reforço da infra-estrutura de sustentação da plataforma, através de uma cortina de estacas pranchas" (Portobras Notícias 1983a:12). Um ano após a inauguração das novas obras, o Vale do Itajaí foi assolado por duas grandes cheias, a de 1983 e a de 1984. O Porto de Itajaí também foi duramente castigado com o desmoronamento de 350 metros de cais acostável, o que danificou três berços. Em seguida à catástrofe, a Portobras providenciou a contratação da Cobrasil, para execução das obras de recuperação (Portobras Notícias 1983b:12). O cronograma das obras foi prejudicado devido à falta de recursos, uma vez que as obras eram todas financiadas pela Portobras, que nos anos 1980 estava se descapitalizando. Somente em 1989, finalmente foram entregues as obras de recuperação, juntamente com algumas melhorias, como a construção do berço cinco e a ampliação do pátio.

\section{Abertura econômica e novos rumos na gestão}

No dia 15 de março de 1990, ou seja, no mesmo dia da posse do presidente Fernando Collor de Mello, foi baixada a Medida Provisória n. 151, que extinguiu cinco autarquias, oito fundações, três empresas públicas e oito sociedades de economia mista. Entre as empresas, estava a Portobras. Após 70 anos de ampliação das funções institucionais dos diversos órgãos que foram criados para gerenciar os portos brasileiros, desde a IFPRC, numa simples medida provisória foi desmontada toda a estrutura da Portobras. Para os portos brasileiros, a extinção da Portobras marcou o início de uma confusão administrativa e uma rápida deterioração das estruturas. Do ponto de vista da hierarquia administrativa, as companhias docas e os demais departamentos simplesmente ficaram "soltos". Era o neoliberalismo nos portos brasileiros.

Mais do que o sistema portuário, o governo Collor pôs fim às políticas de transportes, inclusive com a extinção do Ministério dos Transportes, que foi reduzido a uma secretaria dentro do Ministério da Infra-Estrutura, juntamente com as Comunicações e Minas e Energia. Se a estrutura portuária vinha se deteriorando nos anos de 1980, com o fim da Portobras a situação se complicou mais ainda. As obras foram paralisadas, as licitações foram suspensas e os projetos foram encerrados. No quadro funcional da já extinta Portobras, a situação foi de espanto e de expectativa com o que viria pela frente. A solução imediata foi criar o Departamento de Portos dentro da Secretaria de Transportes, ou seja, a estrutura de uma grande empresa holding transformou-se num departamento.

Os anos de 1990 também significaram épocas de profundas mudanças na economia catarinense, como a reestruturação da indústria cerâmica, o desmonte do parcial do complexo carbonífero, a reestruturação patrimonial no complexo eletro-metal-mecânico, a desverticalização e a retração no segmento têxtil-vestuário e a desnacionalização no complexo agroindustrial. A abertura comercial prejudicou vários segmentos industriais catarinenses com a quebra de cadeias produtivas e o fechamento de várias unidades fabris. É dentro desse cenário de ajustes, abertura e reestruturação que caminhou o Porto de Itajaí nos anos de 1990. 
Em janeiro de 1990, em função da expansão urbana, a Administração do Porto de Itajaí elaborou um estudo para a Portobras sugerindo a construção de um outro porto na cidade instalado no Saco da Fazenda. Seria construído um cais acostável de 740 metros com capacidade para receber até cinco navios. Um dos objetivos era levar o porto para mais próximo do mar. Segundo o Plano de Modernização, a abertura do ingresso de água no Saco da Fazenda contribuiria para a renovação e oxigenação, aumentando a salinidade da água. (Portobras 1990). Contudo, com a extinção da Portobras em março de 1990, o Plano foi abandonado. TABELA 4 - PARTICIPAÇÃODASPRINCIPAISMERCADORIASEXPORTADAS
POR SANTA CATARINA - 1985-2000 (EM \%)

\begin{tabular}{cccccc}
\hline PRODUTOS & 1985 & 1990 & 1995 & 2000 & 2005 \\
\hline Carne congelada & 15,6 & 15,0 & 16,6 & 26,6 & 26,6 \\
Móveis & 0,9 & 1,1 & 6,5 & 11,8 & 7,7 \\
Moto compressor & 4,1 & 9,5 & 9,2 & 9,3 & 5,5 \\
Motores elétricos & - & 1,1 & 2,6 & 5,0 & 4,2 \\
Pisos e azulejos & 0,9 & 2,5 & 3,8 & 5,3 & 3,8 \\
Fumo em folha & 10,3 & 7,0 & 4,4 & 3,3 & 3,7 \\
Papel kraft & 1,3 & 2,1 & 3,4 & 3,7 & 2,9 \\
Refrigeradores & 0,6 & 1,6 & 1,0 & 4,4 & 1,6 \\
Ferro fundido/conexões & 2,4 & 1,3 & 1,5 & 0,5 & 0,7 \\
Farelo de soja & 13,4 & 13,5 & 6,9 & 5,2 & 0,6 \\
Calçados & 5,0 & 1,6 & 0,9 & 0,5 & 0,2 \\
Louça e utensílios & 1,3 & - & 0,5 & 0,5 & 0,2 \\
Outros & 44,2 & 43,7 & 42,7 & 23,9 & 42,3 \\
Total & 100,0 & 100,0 & 100,0 & 100,0 & 100,0 \\
\hline
\end{tabular}

FONTE: MDIC/SECEX/Sistema Aliceweb

Na verdade, a extinção da Portobras abriu uma nova crise no Porto de Itajaí. Os portos brasileiros ficaram ligados ao Departamento Nacional de Portos e Hidrovias, que não tinha recursos e atribuições definidas. Em Santa Catarina, além de Itajaí, o Porto de Laguna também era administrado pela Portobras. A solução temporária e paliativa para ambos veio em dezembro de 1990, com a transferência da administração para a Codesp (Companhia Docas de São Paulo), algo muito estranho para as comunidades de Itajaí e Laguna. A Codesp administraria os portos num período transitório, no máximo por um ano, até a privatização. Porém, essa situação se arrastou por cinco anos. Com a Lei de Modernização dos Portos 8.630/1993, as chances de privatizar o Porto de Itajaí eram maiores. Na época, a administração municipal, os empresários locais e os trabalhadores do Porto de Itajaí exigiam uma solução definitiva para o porto, pois estava ficando insustentável para o terminal, para a cidade e para o estado a forma como a Codesp estava administrando o porto (Administração Hidroviária Docas Catarinense 1997:3). O crescimento constante no volume de carga exigia novos investimentos em equipamentos e ampliação 
do pátio, e a Codesp voltava-se mais para os portos paulistas. Com isso, a morosidade nas tomadas de decisões imprimia um ritmo lento às atividades administrativas do Porto de Itajaí, que por sua vez perdia linhas regulares. (Hoffmann \& Silva 2001).

Finalmente, a resposta veio com a transferência da concessão para a prefeitura municipal em junho de 1995, modelo inspirado na administração do Porto de Rotterdam (Administração Hidroviária Docas Catarinense 1997). Para assumir a concessão, foi criada no dia 16 de junho de 1995 pela Prefeitura Municipal de Itajaí (Lei Municipal 2.970/1995) a Administração Hidroviária Docas Catarinense (ADHOC), que passou a ser responsável pela administração do Porto de Itajaí. No dia $1^{\circ}$ de dezembro de 1997, pelo Convênio de Delegação assinado entre a ADHOC e o Ministério dos Transportes, a ADHOC recebeu a concessão de exploração do porto pelo prazo de 25 anos. E recentemente, em junho de 2000, a Prefeitura Municipal de Itajaí transformou a AHDOC em autarquia municipal, com a denominação de Superintendência do Porto de Itajaí (Lei Municipal 3.513/2000).

Com os adventos da nova administração, as tomadas de decisões foram descentralizadas, iniciando-se uma série de mudanças estruturais para ampliar e agilizar os serviços. Uma das mais importantes foi o arrendamento de 25 anos para a empresa Terminal de Contêineres do Vale do Itajaí S.A. (Teconvi) do berço 1, de 250 metros, e de três áreas para a carga e descarga de contêineres. Também está prevista a construção de mais um berço de 250 metros com 12 metros de profundidade (Revista Portuária 2003:6). A empresa já está em operação, e quando suas obras estiverem totalmente concluídas, basicamente 50,0\% da área do Porto do Itajaí vai ser controlada pela Teconvi e movimentará 80,0\% da carga containerizada (Revista Portuária 2003:9). O porto não foi privatizado por completo, porém metade da sua área foi arrendada para uso exclusivo de uma única empresa, e a ADHOC não terá gerência sobre a Teconvi, nem sobre a área portuária arrendada.

Outro investimento importante no porto foi da Seara Alimentos, com o terminal da Braskarne, que movimenta 240 mil toneladas de alimentos congelados por ano. Itajaí também dispõe de uma Estação Aduaneira de Interior (EADI), a Multilog, do Grupo Portobello, que opera com os regimes aduaneiros e movimenta carga junto ao Porto de Itajaí e ao Aeroporto de Navegantes. Atualmente, a estrutura do porto é a seguinte:

a) cais acostável de 740 metros com 8 metros de profundidade;

b) três armazéns de carga geral, totalizando $15.800 \mathrm{~m}^{2}$;

c) um armazém frigorífico com $1.180 \mathrm{~m}^{2}$;

d) um pátio para contêineres, a céu aberto, com $37.900 \mathrm{~m}^{2}$. 


\begin{tabular}{|c|c|}
\hline CAIS & DESCRIÇÃO \\
\hline Berço 1 & Arrendamento Teconvi S.A. \\
\hline Berço 2 & $\begin{array}{c}\text { Tem atracação de navios de carga geral/reefer, de acordo com disponibilidade } \\
\text { de espaço }\end{array}$ \\
\hline Berço 3 & $\begin{array}{c}\text { Preferência de atracação é para os navios com carga geral para armadores } \\
\text { com serviço regular (liner). }\end{array}$ \\
\hline Berço 4 & $\begin{array}{l}\text { Prioritário para navios full-containers/Teconvi S.A. ou navios full-containers, } \\
\text { roll-on/roll-of (navio adaptado para transportarem automóveis e caminhões) } \\
\text { ou dotados de ponte rolante operados pelos demais operadores portuários, } \\
\text { quando não estiver sendo utilizado pelo Teconvi S.A. }\end{array}$ \\
\hline
\end{tabular}

\section{QUADRO 1 - CARACTERÍSTICAS DO PORTO DE ITAJAÍ - 2004}

FONTE: Porto de Itajaí

Podemos dividir a história da movimentação de cargas do Porto de Itajaí em três períodos. O primeiro período abrangeu todo o século XIX e o início do XX, quando o porto atendia às colônias do Vale do Itajaí. O segundo se estendeu até o final dos anos de 1960, quando predominou a exportação de madeira, e Itajaí era considerado o maior porto madeireiro do Brasil. A terceira fase é a atual, em que predominam as exportações de carga geral, com destaque recente para as cargas containerizadas (Itajaí foi pioneiro no estado a movimentar contêineres, em 1974) e frigorificadas. A consolidação e a internacionalização da indústria catarinense, com o fortalecimento dos grandes grupos empresariais do complexo agroindustrial de carne, papel e celulose, cerâmica, eletro-metal-mecânica e têxtil-vestuário, revitalizou o Porto de Itajaí, transformando-o num porto de carga geral.

Podemos considerar a metade da década de 1970 como o ponto de inflexão para o Porto de Itajaí, como podemos observar na Tabela 5, com relação à movimentação de carga geral, que caiu de 313 mil toneladas em 1960 para 141 mil em 1970, e retoma para 311 mil toneladas em 1980. O dilema era: ou tornava-se apenas um porto pesqueiro ou um porto regulador do Porto de Santos. A dinâmica da economia catarinense fez de Itajaí um porto integrado com a cidade e com a economia estadual.

$$
\begin{gathered}
\text { TABELA } 5 \text { - EVOLUÇÃO DO MOVIMENTO DE CARGA NO PORTO DE } \\
\text { ITAJAÍ - 1955-2000 (EM T) }
\end{gathered}
$$

\begin{tabular}{ccccc}
\hline ANO & GRANEL SÓLIDO & GRANEL LÍQUIDO & CARGA GERAL & TOTAL \\
\hline 1955 & - & 48.903 & 352.430 & 401.333 \\
1960 & 1.000 & 105.655 & 313.945 & 420.600 \\
1965 & 12.129 & 146.846 & 176.799 & 335.774 \\
1970 & 53.025 & 346.186 & 141.528 & 540.739 \\
1975 & 31.858 & 557.163 & 156.566 & 745.587 \\
1980 & 33.140 & 438.933 & 311.007 & 783.080 \\
1985 & 54.598 & 497.536 & 453.815 & 1.005 .949 \\
1990 & 74.279 & 591.349 & 641.461 & 1.307 .089 \\
1995 & 78.540 & 751.315 & 1.111 .827 & 1.941 .682 \\
2000 & 120.124 & 72.501 & 2.042 .992 & 2.235 .617 \\
\hline
\end{tabular}

FONTE: Estatística portuária e relatórios dos órgãos responsáveis pelos portos brasileiros 
TABELA 6 - EVOLUÇÃO DO MOVIMENTO DE EMBARQUE E DESEMBARQUE NO PORTO DE ITAJAÍ - 1920-2000 (EM T)

\begin{tabular}{ccccc}
\hline ANO & $\begin{array}{c}\text { DESEMBARQUE } \\
\text { (LONGO CURSO) }\end{array}$ & $\begin{array}{c}\text { EMBARQUE } \\
\text { (LONGO CURSO) }\end{array}$ & $\begin{array}{c}\text { CABOTAGEM } \\
\text { (TOTAL) }\end{array}$ & TOTAL \\
\hline 1920 & 469 & 234 & 32.436 & 33.139 \\
1925 & 1.198 & - & 48.794 & 49.992 \\
1930 & 2.983 & 485 & 47.881 & 51.349 \\
1935 & 3.141 & 196 & 63.279 & 66.616 \\
1940 & 1.159 & 1.052 & 80.369 & 82.580 \\
1945 & - & 12.365 & 120.114 & 132.479 \\
1950 & 4.054 & 83.006 & - & - \\
1955 & 10.995 & 180.351 & 257.090 & 448.436 \\
1960 & 4.011 & 189.256 & 250.319 & 443.586 \\
1965 & 16.088 & 159.127 & 192.914 & 368.129 \\
1970 & 13.135 & 146.539 & 393.298 & 552.972 \\
1975 & 21.232 & 119.536 & 604.819 & 745.587 \\
1980 & 31.129 & 259.037 & 492.393 & 782.559 \\
1985 & 17.265 & 449.409 & 539.275 & 1.005 .949 \\
1990 & 45.894 & 579.708 & 641.968 & 1.267 .570 \\
1995 & 251.168 & 892.234 & 46.965 & 1.190 .367 \\
2000 & 558.060 & 1.390 .914 & 28.135 & 1.977 .109 \\
\hline
\end{tabular}

FONTE: Estatística portuária e relatórios dos órgãos responsáveis pelos portos brasileiros

\section{Uma periodização possível para a história econômica do Porto de Itajaí}

Tomando como referência o ano de 1905, quando foram iniciadas as obras de melhoramento e observado o movimento da longa duração no Porto de Itajaí no século XX, é possível identificar cinco períodos, destacando a evolução estrutural, a movimentação de carga e a administração:

a) 1905 a 1934 - Porto da colonização e definição do projeto - Nesse momento, o Porto de Itajaí ainda atendia basicamente às demandas das colônias do Vale do Itajaí e tinha uma estrita relação com a sua bacia hidrográfica. O projeto definitivo ainda estava sendo estudado e as obras foram paralisadas por várias vezes. Em 1934, foi rescindido o contrato com a Cobrasil. Em âmbito estadual, o porto era um reflexo do padrão de crescimento da economia catarinense, que era baseado na pequena produção e no capital mercantil.

b) 1934 e 1966 - Especialização e lenta construção - Foi a fase da madeira e da aprovação dos vários orçamentos pelo governo federal. Em 1966, finalmente o Porto de Itajaí foi declarado Porto Organizado, sendo criada a Junta Administrativa do Porto de Itajaí, vinculada à DNPVN. Nesse momento, o porto era o responsável pela exportação de boa parte da madeira catarinense. 
c) 1966 a 1975 - Crise e transição - A crise da madeira também mergulhou o porto numa crise. Porém, novos desafios eram impostos ao porto, como ser transformando num porto pesqueiro ou partir para uma nova especialização. Nesse momento, a economia catarinense já estava pautada num novo padrão de crescimento baseado no grande capital e no planejamento estadual. Os novos rumos dados ao porto impuseram as transformações no Porto de Itajaí, adaptando-o ao novo padrão de crescimento. Em 1975, a Portobras assumiu o porto e criou a Administração do Porto de Itajaí.

d) 1975 a 1995 - Nova especialidade e instabilidade administrativa - Ao longo do período, o Porto de Itajaí foi definindo uma nova especialidade, baseada em carga geral containerizada. No entanto, enquanto eram definidos os novos rumos, o porto passou por instabilidade administrativa. De 1975 a 1990, ficou sob responsabilidade da Portobras e de 1990 a 1995, a gestão foi transferida para a Codesp.

e) 1995 aos dias atuais - Municipalização e expansão acelerada - A partir de 1995, a Prefeitura Municipal de Itajaí assumiu a administração, criando a autarquia municipal AHDOC. Dada a ampliação do comércio externo brasileiro, o Porto de Itajaí rapidamente se adaptou às novas exigências e integrou-se com a economia da Região Sul do Brasil.

\section{Conclusão}

Se fôssemos pensar os portos brasileiros dentro da perspectiva de Braudel (1998), longa duração, e de List (1986), sistema nacional de economia, desde o início do século XIX, são perceptíveis dois movimentos caminhando paralelos. O primeiro é que no sistema portuário brasileiro a oferta sempre andou a reboque da demanda, ou seja, os investimentos feitos nos portos (melhoramento, reaparelhamento e modernização) sempre foram insuficientes para atender ao volume crescente do comércio externo brasileiro. Os investimentos rapidamente maturavam-se seguindo para um estrangulamento, exigindo mais enovos investimentos, porém, mais complexo e caro do que o anterior. Como a demanda anda à frente, o problema do estrangulamento é constantemente reposto num nível mais complexo. O segundo movimento é que, mesmo ao lado dos constantes estrangulamentos, foi se formando no Brasil um sistema portuário nacional integrado. Esse sistema acompanhou e contribuiu na formação do sistema nacional de economia. Rodovias, energia, telefonia, siderurgia, sistema de crédito e portos estão todos integrados e formam um sistema nacional de economia.

Já com relação a Santa Catarina, no último quartel do século XIX as colônias catarinenses imprimiram um novo ritmo à economia regional e ajustaram os portos para escoarem a produção das pequenas atividades mercantis. Foi essa a relação do Porto de Itajaí com as colônias do Vale. Com a especialização regional catarinense durante a primeira metade do século XX, centrada em erva-mate, madeira, têxtil, carvão e alimentos, os portos catarinenses também se especializaram em determinados segmentos. Itajaí transformou-se no maior porto madeireiro do país. Com a diversificação produtiva da economia catarinense nos anos de 1940 e 1950 pautadas na indústria metal-mecânica, cerâmica, papel e pasta mecânica e na formação do complexo agroindustrial, os portos catarinenses, sobretudo Itajaí e São Francisco do Sul, tiveram que começar a se ajustar às novas dinâmicas. 
Com a integração e a consolidação da indústria catarinense a partir dos anos de 1960, comandado pelo grande capital industrial e agroindustrial, e a queda nas exportações da madeira nos anos de 1970, o Porto de Itajaí se especializou em carga geral e frigorificada. Os ajustes recessivos e a abertura comercial nos anos de 1990 colocaram novos desafios para o Porto de Itajaí. A municipalização do porto em 1995 afastou a possibilidade de privatizá-lo, e o aumento exponencial do fluxo de mercadorias exportadas e importadas colocou o porto num novo patamar de competitividade.

Enquanto a integração do porto era apenas com o Vale do Itajaí, a pequena navegação fluvial e os rios cumpriam suas funções de via de comunicação entre o litoral e as colônias. A expansão da pequena EFSC (Estrada de Ferro Santa Catarina) no sentido leste não se constituiu num corredor de transporte para o porto, pois só chegou no cais do porto em 1961 e foi desativada em 1970. A crise ferroviária brasileira somou-se à crise da madeira, tornando a EFSC ainda mais deficitária. O velho barco a vapor e a locomotiva foram suplantados pelos caminhões, e o rio e os trilhos, pela rodovia. Com a consolidação e a internacionalização da economia catarinense, a hinterland do Porto de Itajaí se ampliou, e, como não poderia ser muito diferente, as rodovias se constituíram como os únicos corredores de transporte.

Dois fatores vêm contribuindo para o crescimento acelerado do porto nos últimos dez anos: a) o aumento do comércio externo brasileiro, que está incentivando a ampliação de vários portos; e b) a eficiência da administração pública municipal. O porto e a cidade já passaram por vários momentos de crise, como a queda nas exportações de madeira, o fim dos incentivos para a pesca, o desmonte nacional da indústria naval, os desastres causados pelas cheias do Rio Itajaí-Açu e o fim da Portobras. Hoje, a cidade vive um virtuoso período de crescimento pautado basicamente em dois pilares: a expansão do porto e a ampliação da pesca industrial. O ressurgimento da indústria naval nacional é a nova promessa para a cidade e, talvez, se torne o terceiro pilar do crescimento econômico de Itajaí.

\section{Fontes e referências}

a) Mensagens e relatórios

ADMINISTRAÇÃO HIDROVIÁRIA DOCAS CATARINENSES (1997). Porto de Itajaí. Itajaí.

BRASIL (1896). Relatório apresentado ao presidente da República dos Estados Unidos do Brasil pelo ministro da Indústria, Viação e Obras Públicas, Antonio Olyntho dos Santos, em maio de 1896. Rio de Janeiro: Imprensa Nacional.

. (1897). Relatório do Ministério da Indústria, Viação e Obras Públicas. Rio de Janeiro: Imprensa Nacional.

. (1904). Relatório do Ministério da Indústria, Viação e Obras Públicas. Rio de Janeiro: Imprensa Nacional. 
. (1906). Relatório do Ministério da Indústria, Viação e Obras Públicas. Rio de Janeiro: Imprensa Nacional.

. (1907). Relatório do Ministério da Indústria, Viação e Obras Públicas. Rio de Janeiro: Imprensa Nacional.

. (1909). Relatório do Ministério da Indústria, Viação e Obras Públicas. Rio de Janeiro: Imprensa Nacional.

. (1911). Relatório apresentado ao presidente da República dos Estados Unidos do Brasil pelo ministro da Indústria, Viação e Obras Públicas, J. J. Seabra. Rio de Janeiro: Imprensa Nacional.

. (1918). Relatório apresentado ao presidente da República dos Estados Unidos do Brasil pelo ministro da Viação e Obras Públicas, Augusto Tavares de Lyra, no ano de 1917. Rio de Janeiro: Imprensa Nacional.

. (1922). Relatório apresentado ao presidente da República dos Estados Unidos do Brasil, Epitácio Pessoa, pelo ministro da Viação e Obras Públicas, J. Pires do Rio, no ano de 1922. Rio de Janeiro: Imprensa Nacional.

. (1924). Relatório apresentado ao presidente da República Arthur da Silva Bernardes pelo ministro da Viação e Obras Públicas, Francisco Sá, no ano de 1922. Rio de Janeiro: Imprensa Nacional.

DEPARTAMENTO NACIONAL DE PORTOS E NAVEGAÇÃO (1935). Relatório da comissão de estudo do Porto de Itajaí e Rio Cachoeira. Rio de Janeiro. (Elaborado por Thiers de Lemo Fleming).

. (1934). Inspeção à conserva do material nos portos de Itajaí e Laguna. Rio de Janeiro (Elaborado por F. B. Gallotti).

INSTITUTO NACIONAL DE PESQUISAS HIDROVIÁRIAS (1983). Evolução históricomorfológica do estuário do Rio Itajaí-Açu e suas implicações no Porto de Itajaí. Rio de Janeiro: Portobrás.

. (1985). Relatório dos levantamentos topo-hidrográficos na região do novo projeto do cais de Itajaí-SC. Rio de Janeiro: Portobrás.

INSPETORIA FEDERAL DE PORTOS, RIOS E CANAIS (1924). Relatório da viagem de inspeção aos portos de Santa Catarina. Rio de Janeiro. (Elaborado por Luiz José Le Cocq de Oliveira).

. Sindicância nas obras do Porto de Itajaí. Rio de Janeiro: Jornal do Commercio, 1932.

MINISTÉRIO DA VIAÇÃO E OBRAS PÚBLICAS (1922). Relatório dos serviços prestados pela Inspetoria Federal de Portos, Rios e Canais no ano de 1920 apresentado ao ministro da Viação e Obras Públicas pelo inspetor Federal Lucas Bicalho. Rio de Janeiro: Imprensa Nacional.

.(1928). Relatório dos serviços executados pela Inspetoria Federal de Portos, Rio e Canais ao ministro da Viação e Obras Públicas Victor Konder pelo inspetor Federal Hidelbrando de Araújo Góes no ano de 1927. Rio de Janeiro: Tipografia Jornal do Comércio, 1. parte.

. (1928). Relatório dos serviços executados pela Inspetoria Federal de Portos, Rio e Canais ao ministro da Viação e Obras Públicas Victor Konder pelo inspetor Federal Hidelbrando de Araújo Góes no ano de 1927. Rio de Janeiro: Tipografia Jornal do Comércio, $2^{\text {a }}$. parte.

. (1932). Relatório dos serviços executados pela Inspetoria Federal de Portos, Rio e Canais ao ministro da Viação e Obras Públicas Victor Konder pelo inspetor Federal Hidelbrando de Araújo Góes no ano de 1928. Rio de Janeiro: Tipografia Jornal do Comércio. 
. (1936). Relatório dos serviços executados durante o ano de 1935 apresentado ao ministro da Viação e Obras Públicas João Marques dos Reis pelo diretor Frederico Cezar Burlamaqui. Rio de Janeiro: Oficina dos Correios e Telégrafos.

. (1937). Relatório dos serviços executados durante o ano de 1936 apresentado ao ministro da Viação e Obras Públicas João de Marques dos Reis pelo diretor Frederico Cezar Burlamaqui. Rio de Janeiro: Oficina dos Correios e Telégrafos.

. (1939). Relatório dos serviços executados em 1938 apresentado ao ministro da Viação e Obras Públicas João de Mendonça Lima pelo diretor Frederico Cezar Burlamaqui. Rio de Janeiro: Gráfica do DNPN.

. (1954). Relatório dos serviços executados em 1949 apresentado ao ministro da Viação e Obras Públicas pelo diretor geral Clovis Macedo Cortes. Rio de Janeiro: Imprensa Nacional.

MINISTÉRIO DOS TRANSPORTES (1974). Plano Diretor Portuário do Brasil e Programa Decenal de Reaparelhamento e Expansão dos Portos 1975 a 1984. Brasília: Portobras.

MINISTÉRIO DOS TRANSPORTES (1986). Plano de Desenvolvimento Portuário: Porto de Itajaí. Brasília: Portobras, v. A.

MINISTÉRIO DOS TRANSPORTES (1979). Plano Diretor Portuário do Brasil: Porto de Itajaí. Brasília: Portobras.

MINISTÉRIO DOS TRANSPORTES (1986). Plano de Desenvolvimento Portuário: Porto de Itajaí. Brasília: Portobras, v. C.

PORTOBRÁS (1990). Plano de Modernização Porto de Itajaí. Itajaí: Administração do Porto de Itajaí.

SANTA CATARINA (1913). Mensagem apresentada ao Congresso Representativo do Estado de Santa Catarina pelo Governador Vidal José de Oliveira Ramos. Florianópolis: Tipografia do Dia.

b) Decretos

BRASIL (1903). Decreto n. 4.859 de 8 de junho de 1903. URL [On line]: http://www.senado. gov.br/servlets. Acesso em: 18 de agosto de 2004.

. (1918). Decreto n. 12.907 de 6 de março de 1918. URL [On line]: http://www. senado.gov.br/servlets. Acesso em: 10 de outubro de 2004.

. (1919). Decreto n. 13.539 de 9 de abril de 1919. URL [On line]: http://www.senado. gov.br/servlets. Acesso em: 10 de outubro de 2004.

. (1926). Decreto n. 17.344 de 9 de junho de 1926. URL [On line]: http://www. senado.gov.br/servlets. Acesso em: 10 de outubro de 2004.

(1928). Decreto n. 18.243 de 11 de maio de 1928. URL [On line]: http://www. senado.gov.br/servlets. Acesso em: 10 de outubro de 2004.

. (1934). Decreto n. 24.414 de 19 de junho de 1934. URL [On line]: http//www. senado.gov.br/servlets. Acesso em: 10 de outubro de 2004.

. (1938). Decreto n. 2.665 de 13 de maio de 1938. URL [On line]: http//www.senado. gov.br/servlets. Acesso em: 10 de outubro de 2004.

. (1941). Decreto n. 7.881 de 18 de setembro de 1941. URL [On line]: http//www. senado.gov.br/servlets. Acesso em: 10 de outubro de 2004. 
. (1943). Decreto n. 13.558 de 30 de setembro de 1943. URL [On line]: http//www. senado.gov.br/servlets. Acesso em: 10 de outubro de 2004.

. (1946). Decreto n. 21.215 de 29 de maio de 1946. URL [On line]: http://www. senado.gov.br/servlets. Acesso em: 10 de outubro de 2004.

. (1947). Decreto n. 23.121 de 28 de maio de 1947. URL [On line]: http//www. senado.gov.br/servlets. Acesso em: 10 de outubro de 2004.

. (1948a). Decreto n. 24.536 de 19 de fevereiro de 1948. URL [On line]: http//www. senado.gov.br/servlets. Acesso em: 10 de outubro de 2004.

. (1948b). Decreto n. 26.112 de 30 de dezembro de 1948. URL [On line]: http//www. senado.gov.br/servlets. Acesso em: 10 de outubro de 2004.

. (1949). Decreto n. 26.389 de 23 de fevereiro de 1949. URL [On line]: http//www. senado.gov.br/servlets. Acesso em: 10 de outubro de 2004.

. (1950). Decreto n. 28.468 de 5 de agosto de 1950. URL [On line]: http://www. senado.gov.br/servlets. Acesso em: 10 de agosto de 2004.

. (1954). Decreto n. 20.396 de 14 de janeiro de 1954. URL [On line]: http//www. senado.gov.br/servlets.. Acesso em: 10 de outubro de 2004.

. (1960). Decreto n. 49.758 de 31 de dezembro de 1960. URL [On line]: http://www. senado.gov.br/servlets. Acesso em: 10 de outubro de 2004.

. (1966). Decreto n. 58.780 de 28 de junho de 1966. URL [On line]: http://www. senado.gov.br/servlets. Acesso em: 10 de agosto de 2004.

. (1993). Lei n. 8.630 de 25 de fevereiro de 1993. URL [On line]: http://www.senado. gov.br/servlets. Acesso em: 10 de agosto de 2004.

ITAJAÍ (1995). Lei n. 2.970 de 16 de junho de 1995. URL [On line]: http://www. leismunicipais.com.br/sc/itajai. Acesso em: 10 de agosto de 2004.

. (2000). Lei n. 3.513 de 6 de junho de 2000. URL [On line]: http://www. leismunicipais.com.br/sc/itajai. Acesso em: 10 de agosto de 2004.

c) Jornais e revistas

BOA INFRA-ESTRUTURA GARANTE CRESCIMENTO DO PORTO (2003). Revista Portuária. Itajaí, ano IV, n. 40.

TECONVI SUPERA EXPECTATIVA E AMPLIA ÁREA DE OPERAÇÃO (2003). Revista Portuária. Itajaí, ano IV, n. 42.

SEVERO ENTRE OBRAS DO PORTO DE ITAJAÍ (1983a). Portobrás Notícias. Brasília, n. 31 , jun.

Cr\$ 1,9 BI PARA ITAJAÍ VOLTAR A PLENA CARGA (1983b). Portobrás Notícias. Brasília, n. 35, out.

d) Livros, dissertações e outros

AVÉ-LALLEMANT, R. (1980). Viagens pelas províncias de Santa Catarina, Paraná e São Paulo (1858). Belo Horizonte: Itatiaia; São Paulo: Editora da USP.

BRAUDEL, F. (1998). Civilização material, economia e capitalismo - século XV-XVIII: o tempo do mundo. São Paulo: Martins Fontes. 
BRITO, P. J. M. (1829). Memória politica sobre a capitania de Santa Catharina. Lisboa: Academia Real das Ciências.

CANO, W. (1990). Raízes da concentração industrial em São Paulo. São Paulo: HUCITEC.

CARDOSO DE MELLO, J. M. (1988). O capitalismo tardio: contribuição à revisão crítica da formação e do desenvolvimento da economia brasileira. São Paulo: Brasiliense.

CASTRO, A. B. de (1980). Sete ensaios sobre a economia brasileira. Rio de Janeiro: Forense Universitária.

CENTRO DE ASSISTÊNCIA GERENCIAL DE SANTA CATARINA (1980). Evolução histórico-econômica de Santa Catarina: estudos das alterações estruturais (século XVII-1960). Florianópolis: CEBRAE/CEAG-SC.

COBRASIL (1931). Sindicância efetuada nas obras do Porto de Itajaí apresentada à Inspetoria Federal de Portos, Rios e Canais. Rio de Janeiro: Jornal do Commercio.

COELHO, M. J. de A. (1856). Memória histórica da província de Santa Catarina. Desterro: Imprensa Desterrens de J. J. Lopes.

D’AVILA, E. (1982). Pequena história de Itajaí. Itajaí: Fundação Genésio Miranda Lins.

GÓES, H. A. (1930). Problemas portuários. Rio de Janeiro: Inspetoria de Porto, Rio e Canais.

GOULARTI FILHO, A. (2002). Formação econômica de Santa Catarina. Florianópolis: Cidade Futura.

. (2006). "Melhoramentos, reaparelhamentos e modernização dos portos brasileiros: a longa e constante espera." In: Anais do XI Encontro Nacional de Economia Política. Vitória: SEP.

HOFFMANN, V. \& SILVA, S. N. da (2001). Porto de Itajaí: impacto da abertura de mercado e conseqüente municipalização. Itajaí: Editora da Univali.

LENZI, R. M. (Org.) (2002). Itajaí - outras histórias. Itajaí: Prefeitura Municipal/Secretaria de Educação \& Fundação Genésio Miranda Lins.

LISBOA, A. (1922). Portos do Brasil. Rio de Janeiro: O Norte.

LIST, G. F. (1986). Sistema nacional de economia política. São Paulo: Nova Cultural.

MAMIGONIAN, A. (1965). "Estudo geográfico das indústrias de Blumenau." Revista Brasileira de Geografia 27 (3): 389-481, jul-set.

MARX, K. (1983). Contribuição à crítica da economia política. São Paulo: Martins Fontes.

MOREIRA, S. M. (1995). Porto de Itajai: da gênese aos dias atuais. Florianópolis: Dissertação de mestrado, Universidade Federal de Santa Catarina, Programa de PósGraduação em Geografia.

Submissão: 6 de dezembro de 2006 Primeira resposta: 11 de fevereiro de 2007

Aceite: 17 de fevereiro de 2007 


\section{ANEXO}

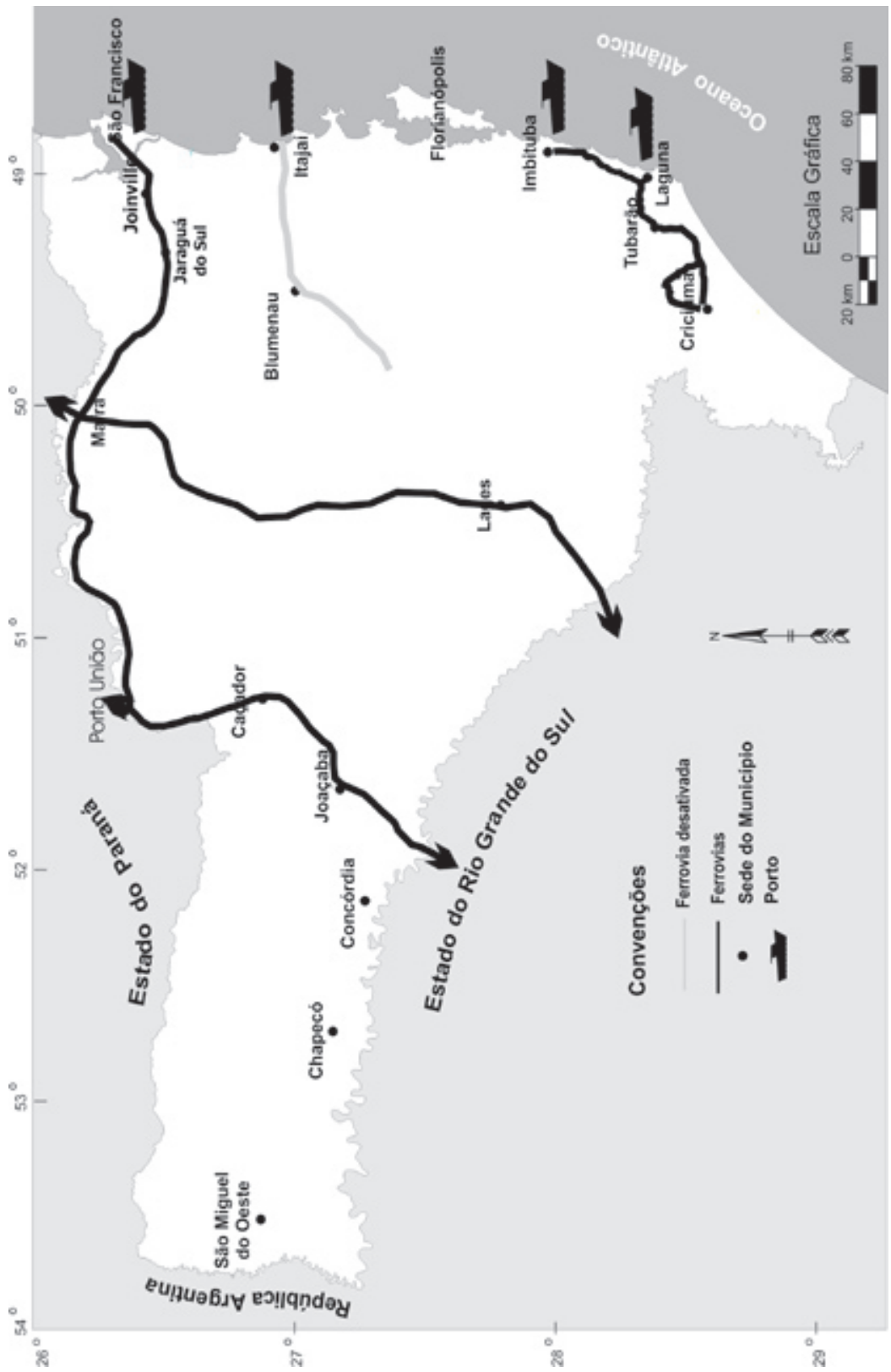

FIGURA 1 - MAPA FERROVIÁRIO E PORTUÁRIO DE SANTA CATARINA 